\title{
MicroRNA-106b functions as an oncogene in renal cell carcinoma by affecting cell proliferation, migration and apoptosis
}

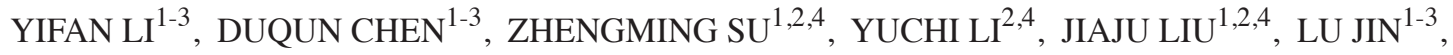 \\ MIN SHI $^{2}$, ZHIMAO JIANG ${ }^{2}$, ZHENGYU QI ${ }^{2}$, YAOTING GUI ${ }^{2}$, SHANGQI YANG ${ }^{1,2}$, \\ XIANGMING MAO ${ }^{1,2}$, XIONGHUI WU ${ }^{1,2}$ and YONGQING LAI ${ }^{1,2}$ \\ ${ }^{1}$ Department of Urology, Peking University Shenzhen Hospital; ${ }^{2}$ Department of Urology, \\ The Guangdong and Shenzhen Key Laboratory of Male Reproductive Medicine and Genetics, \\ Peking University Shenzhen Hospital, Shenzhen, Guangdong 518036; \\ ${ }^{3}$ Department of Urology, Anhui Medical University, Hefei, Anhui 230032; \\ ${ }^{4}$ Department of Urology, Shantou University Medical College, Shantou, Guangdong 515041, P.R. China
}

Received January 18, 2015; Accepted November 5, 2015

DOI: $10.3892 / \mathrm{mmr} .2015 .4656$

\begin{abstract}
Kidney cancer is the 14th most common cancer in the world and its prognosis remains poor due to difficult early detection and treatment. Therefore, the identification of biomarkers for early-stage renal cell carcinoma (RCC) is important. MicroRNA-106b (miR-106b) has been described as an oncogene in several types of human cancer. Previous microarray studies have suggested that miR-106b was significantly upregulated in RCC tissues compared with paired normal kidney tissues and may be a promising biomarker for the prediction of early metastasis following nephrectomy. The present study aimed to determine the expression and function of miR-106b in RCC. The expression of miR-106b in RCC tissues and cells, and in paired normal tissues and cells was determined by reverse transcription quantitative polymerase chain reaction, based on the previous sequencing results of miRNAs. Furthermore, a wound scratch assay, MTT assay and flow cytometry were performed to examine the functions of miR-106b on cell migration, proliferation and apoptosis. The results demonstrated that miR-106b was upregulated in RCC tissues and cell lines compared with control normal tissues and cell lines. Downregulation of miR-106b with a synthesized inhibitor suppressed cell migration and proliferation and induced renal cancer cell apoptosis, suggesting that miR-106b can be characterized as an oncogene in RCC. To the best of our knowledge, the present study was the first to reveal that
\end{abstract}

Correspondence to: Professor Yongqing Lai or Professor Xionghui Wu, Department of Urology, Peking University Shenzhen Hospital, 1120 Lianhua Road, Shenzhen, Guangdong 518036, P.R. China E-mail: yqlord@163.com

E-mail: 13802260619@163.com

Key words: microRNA-106b, renal cell carcinoma, biomarker, oncogene
miR-106b is upregulated and affects cellular migration, proliferation and apoptosis in RCC. Further studies are required to examine the role and target genes of miR-106b in RCC.

\section{Introduction}

Kidney cancer is the 14 th most common cancer in the world, and its incidence and mortality has plateaued in North America and Europe in previous years and continues to increase in incidence in developing countries $(1,2)$. The 5-year survival rate of renal cell carcinoma (RCC) is significantly higher for stage I disease than stage III disease, underscoring the importance of early detection and treatment of RCC. However, early detection and treatment is difficult, since RCC is characterized by a lack of early-warning signs, protean clinical manifestations, and resistance to radiotherapy and chemotherapy $(3,4)$. Therefore, the identification of biomarkers for early-stage RCC is important. However, no accurate biomarker for RCC currently exists (5).

Kidney cancer is not a single disease but a number of different types of cancer that occur in the kidney, each caused by a different gene with a distinct histology and clinical course that responds differently to therapy (6). These known kidney cancer genes, VHL, MET, FLCN, TSC1, TSC2, $F H$ and $S D H$, are all possibly regulated by microRNAs (miRNAs) through translational inhibition and/or mRNA degradation (7). There have been an increasing number of studies focusing on the role of miRNAs in RCC and their clinical and pathogenetic significance (8-10). Mutations in the miRNA processing machinery as well as deregulated miRNA expression are observed in a number of different human cancer types, including RCC (8). Dysregulated miRNAs identified by array-based miRNA profiling not only discriminate RCC from normal kidney tissue, but also distinguish different RCC histological subtypes. Specific miRNAs implicated in the pathogenesis of RCC provide a possible new target or tool for clear-cell renal cell carcinoma (ccRCC) therapy $(9,10)$. 
Previous microarray studies suggested that microRNA-106b (miR-106b) was significantly upregulated in RCC tissues compared with paired normal kidney tissues (11-14). Slaby et al identified a prognostic significance of miR-106b, which, following validation on a larger group of patients, may be useful as a promising biomarker for the prediction of early metastasis following nephrectomy (14). It has been reported that miR-106b is widely upregulated in various types of human malignancy, including head and neck (15), ovarian (16), prostate (17), colon (18), gastric (19), laryngeal (20) and brain (21) cancer by comprehensive miRNA profiling. However, the expression of miR-106b requires quantification and the function of miR-106b in RCC cells requires elucidation. The aim of present study was to determine the upregulation of miR-106b in RCC tissues and cell lines compared with the controls and describe the function of miR-106b in RCC tumorigenesis.

\section{Materials and methods}

Clinical specimens, cell culture and RNA isolation. RCC tissues and adjacent normal tissues were obtained from the Department of Urology, Peking University Shenzhen Hospital (Shenzhen, China) and the Anhui Medical University First Affiliated Hospital (Anhui, China) between February 2006 and February 2011, in accordance with Institutional Review Board-approved protocol for human specimen collection and for the use of these materials and associated clinical information for research purposes. The adjacent normal tissues, $\sim 5 \mathrm{~cm}$ from the edge of the tumor, were confirmed by two experienced pathologists. Once dissected, all samples were stored at $-80^{\circ} \mathrm{C}$ in RNAlater (Qiagen, Valencia, CA, USA) for further research. No treatment was administered prior to surgery. All the specimens were evaluated according to the 2010 American Joint Committee on Cancer staging system (22). The clinicopathological information of all the patients is summarized in Table I.

RCC cell lines (786-O and ACHN) and human embryonic kidney 293T (HEK-293T) cells were obtained from the Guangdong and Shenzhen Key Laboratory of Male Reproductive Medicine and Genetics (Shenzhen, China). All cells were cultured in Dulbecco's modified Eagle's medium (DMEM; Gibco; Thermo Fisher Scientific, Inc., Waltham, MA, USA), with $10 \%$ fetal bovine serum (Gibco; Thermo Fisher Scientific, Inc.), $1 \%$ antibiotics $[100 \mathrm{U} / \mathrm{ml}$ penicillin and $100 \mathrm{mg} / \mathrm{ml}$ streptomycin sulfates (Gibco; Thermo Fisher Scientific, Inc.)] and $1 \%$ glutamate (Gibco; Thermo Fisher Scientific, Inc.), and then incubated at $37^{\circ} \mathrm{C}$ in a humidified chamber containing $5 \% \mathrm{CO}_{2}$.

Total RNA, including miRNA was extracted from 35 paired RCC samples and adjacent normal tissue and cells using TRIzol ${ }^{\circledR}$ (Invitrogen: Thermo Fisher Scientific, Inc.) and purified using the RNeasy ${ }^{\circledR}$ Maxi kit (Qiagen), according to the manufacturer's instructions. The RNA samples with 260/280 ratios of 1.8-2.0 were used for further experiments.

Reverse transcription quantitative polymerase chain reaction $(R T-q P C R)$. To quantify the expression level of miR-106b in tissues and cells, RT-qPCR was performed. cDNA was obtained from RNA by using the miScript II RT kit (Qiagen). cDNA templates were diluted 10 times and
Table I. Clinicopathological features in renal cell carcinoma patients.

\begin{tabular}{lc}
\hline Characteristic & Number of cases \\
\hline Mean age range (years) & $50(27-70)$ \\
Gender & \\
Male & 25 \\
Female & 10 \\
Histological type & \\
Clear cell & 26 \\
Papillary & 9 \\
pT stage & \\
T1 & 20 \\
T2 & 14 \\
T3+T4 & 1 \\
Fuhrman grade & \\
I & 10 \\
II & 15 \\
III & 8 \\
IV & 2 \\
AJCC clinical stages & \\
I & 19 \\
II & 14 \\
III+IV & 2 \\
\hline
\end{tabular}

pT, primary tumor; AJCC, American joint committee on cancer.

then used for RT-qPCR. RT-qPCR was performed with the miScript SYBR ${ }^{\circledR}$ Green PCR kit (Qiagen, Valencia, CA, USA) according to the manufacturer's instructions on the Roche LightCycler 480 Real-Time PCR System (Roche Applied Science, Indianapolis, IN, USA). The cycling conditions were as follows: $95^{\circ} \mathrm{C}$ for $15 \mathrm{~min}$; and 40 cycles of $94^{\circ} \mathrm{C}$ for $15 \mathrm{sec}, 55^{\circ} \mathrm{C}$ for $30 \mathrm{sec}$ and $72^{\circ} \mathrm{C}$ for $30 \mathrm{sec}$. The expression levels are shown as fold differences relative to the U6, which were calculated using the following formula: Relative quantification $(\mathrm{RQ})=2^{-\Delta \Delta \mathrm{Cq}}\left[\Delta \Delta \mathrm{Cq}=\left(\right.\right.$ meanCq $_{\mathrm{tumor}}-$ meanCq $\left._{\mathrm{control}}\right)-$ $\left(\right.$ meanCq $\mathrm{Cq}_{\text {normal }}-$ meanCq $\left.\left.\mathrm{q}_{\text {control }}\right)\right]$. The primer sequences are summarized in Table II.

Cell transfection. For upregulation of miR-106b, the cancer cell lines were transfected with synthesized miR-106b mimics (Shanghai GenePharma Co., Ltd., Shanghai, China) using Lipofectamine 2000 (Invitrogen; Thermo Fisher Scientific, Inc.), which were mixed in Opti-MEM ${ }^{\circledR}$ I Reduced Serum Medium (Gibco; Thermo Fisher Scientific, Inc.) according to the manufacturer's instructions following plating for $24 \mathrm{~h}$. The miR-106b inhibitor $(200,100$ and 5 pmol) or a negative control (NC) was transfected into RCC cells in 6-well, 12-well and 96-well plates, respectively, for 4-6 h. The sequences of the miR-106b inhibitor and NC are summarized in Table II.

Cell scratch assay. The migratory ability of 786-O and ACHN cells was assessed by wound scratch assay in vitro. Approximately $3 \times 10^{5}$ cells were seeded per 12 -well dish. After 
Table II. Sequences of primers and miRNAs.

\begin{tabular}{ll}
\hline Name & \multicolumn{1}{c}{ Sequence } \\
\hline miR-106b & Forward: 5'-TAAAGTGCTGACAGTGCAGAT-3' \\
& Reverse: Universal Primer, miScript SYBR ${ }^{\circledR}$ Green PCR kit \\
U6 & Forward: 5'-CTCGCTTCGGCAGCACA-3' \\
& Reverse: 5'-ACGCTTCACGAATTTGCGT-3' \\
miR-106b inhibitor & 5'-AUCUGCACUGUCAGCACUUUA-3' \\
NC & 5'-CAGUACUUUUGUGUAGUACAA-3'
\end{tabular}

miR, microRNA; NC, negative control.

$6 \mathrm{~h}$ of transfection, a sterile $200 \mu \mathrm{l}$ pipette tip was used to scrape a clear line through the cell layer. The cells were then rinsed with phosphate-buffered saline (PBS) and cultured in serum-free DMEM. Images of the scratches were acquired, using a digital camera system, 0 and $48 \mathrm{~h}$ after the scratches were made (IX71; Olympus Corporation, Tokyo, Japan). The experiments were performed in triplicate and repeated more than three times.

3-(4,5-dimethylthiazol-2-yl)-2,5-diphenyltetrazolium bromide $(M T T)$ assay. The MTT (5 mg/ml) assay (Sigma-Aldrich, St. Louis, MO, USA) was used to analyze cell proliferation. 786-O and ACHN cells (5,000 cells/well) were plated into 96-well plates with five replicate wells of each condition. Each well was assessed at $0,24,48$ or $72 \mathrm{~h}$ post-transfection. Prior to measurement, $20 \mu \mathrm{l}$ MTT was added to cells and incubated at $37^{\circ} \mathrm{C}$ in a humidified chamber containing $5 \% \mathrm{CO}_{2}$ for $6 \mathrm{~h}$. Subsequently, the MTT medium mixtures were discarded and $120 \mu \mathrm{l}$ dimethyl sulfoxide (Sigma-Aldrich, Shanghai, China) was added. Following agitation for $30 \mathrm{~min}$ at room temperature, the absorbance was measured using a Model 680 enzyme-linked immunosorbent assay microplate reader (Bio-Rad, Hercules, CA, USA) at a wave length of $490 \mathrm{~nm}$ (with $630 \mathrm{~nm}$ as the reference wave length).

Cell apoptosis assay. $786-\mathrm{O}$ or ACHN $\left(3 \times 10^{5}\right)$ cells were plated in 6-well plates for the cell apoptosis assay. At $48 \mathrm{~h}$ post-transfection, the cells, including floating cells, were harvested, washed twice with $4^{\circ} \mathrm{C}$ PBS and resuspended in $100 \mu \mathrm{l} 1 \mathrm{X}$ binding buffer and stained with $3 \mu \mathrm{l}$ propidium iodide and $5 \mu \mathrm{l}$ Annexin V-fluorescein isothiocyanate (Invitrogen; Thermo Fisher Scientific, Inc.) for $15 \mathrm{~min}$ at room temperature. Flow cytometry (EPICS X1-4; Beckman Coulter, Inc., Brea, CA, USA) was used to quantify the percentage of apoptotic cells within 30 min after staining and $400 \mu \mathrm{l} 1 \mathrm{X}$ binding buffer was added to each sample prior to measurement. Each experiment was performed at least three times.

Statistical analysis. All data are presented as the mean \pm standard deviation from three independent experiments. Statistical analysis was performed with the SPSS 19.0 statistical software package (SPSS, Inc., Chicago, IL, USA). Statistical significance was determined using Student's t-test.
For the comparison of miR-106b expression levels in matched tumor/normal samples, paired t-test was used. $\mathrm{P}<0.05$ was considered to indicate a statistically significant difference.

\section{Results}

miR-106b is highly expressed in human RCC clinical specimens and RCC cell lines. RT-qPCR was used to quantify the expression of miR-106b in 35 paired ccRCC specimens and normal specimens. The results demonstrated that miR-106b was significantly upregulated in $23 / 35$ of RCC specimens (Fig. 1A), with an average of 2.17-fold increase in expression $(\mathrm{P}<0.01$; Fig. 1B). The high expression of miR-106b was in accordance with the results of previous miRNA profiling in RCC (11-14).

The expression of miR-106b was also analyzed in RCC cell lines (786-O and ACHN) and HEK-293T cells by RT-qPCR. miR-106b expression was significantly higher in 786-O and ACHN cells $(\mathrm{P}<0.01$ and $\mathrm{P}<0.01)$ compared with that in $293 \mathrm{~T}$ cells, which is in accordance with the expression pattern of miR-106b in tissues (Fig. 2A). In addition, in order to validate the transfection efficiency of the miR-106b inhibitor in 786-O and ACHN cells, RT-qPCR was performed. As shown in Fig. 2B, the expression of miR-106b was suppressed by 84.4 and $67.5 \%$ in $786-\mathrm{O}$ and ACHN cells, respectively.

Suppression of miR-106b inhibits 786-O and ACHN cell migration. The effects of suppression of miR-106b expression on cell migration in RCC cells were assessed by wound scratch assay. As shown in Fig. 3A, the wound widths of the cells transfected with the miR-106b inhibitor were wider than cells transfected with the NC after 48 h. Statistical analysis demonstrated that the migratory distances of the miR-106b inhibitor group were significantly decreased by $44.2(\mathrm{P}<0.01)$ and $21.3 \%(\mathrm{P}<0.01)$ in $786-\mathrm{O}$ and $\mathrm{ACHN}$ cells, compared with the NC group (Fig. 3B). These results suggested that downregulation of miR-106b inhibited the migratory ability of RCC cells.

Downregulation of miR-106b suppresses 786-O and ACHN cell proliferation. The effect of downregulation of miR-106b on cell proliferation in RCC was analyzed by an MTT assay. Optical density values of the miR-106b inhibitor group and NC group were measured at $0,24,48$ and $72 \mathrm{~h}$ after transfection. 

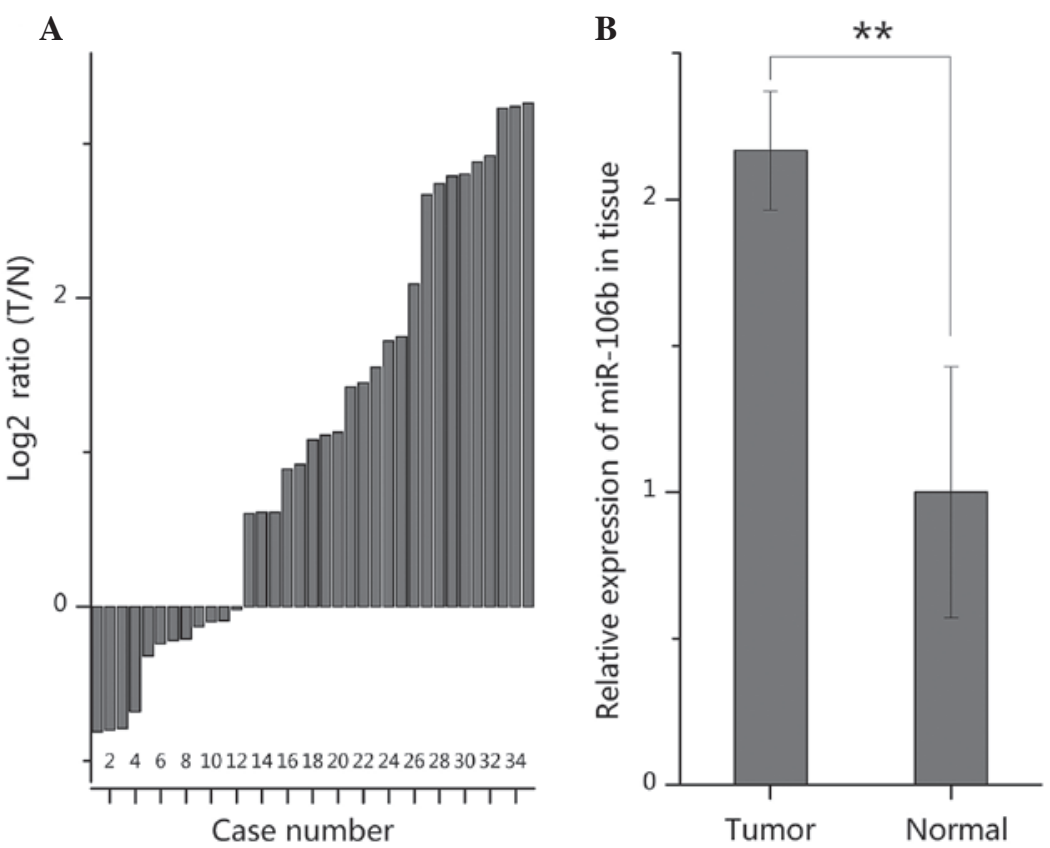

Figure 1. Expression of miR-106b in 35 paired RCC tissues and adjacent normal tissues. (A) Log2 ratios of miR-106b expression in 35 paired RCC tissues (T) to normal kidney tissues (N). (B) Relative expression of miR-106b in RCC (Tumor) and normal tissues (Normal) ${ }^{* *} \mathrm{P}<0.001$. miR-106b, microRNA-106b, RCC, renal cell carcinoma.

A

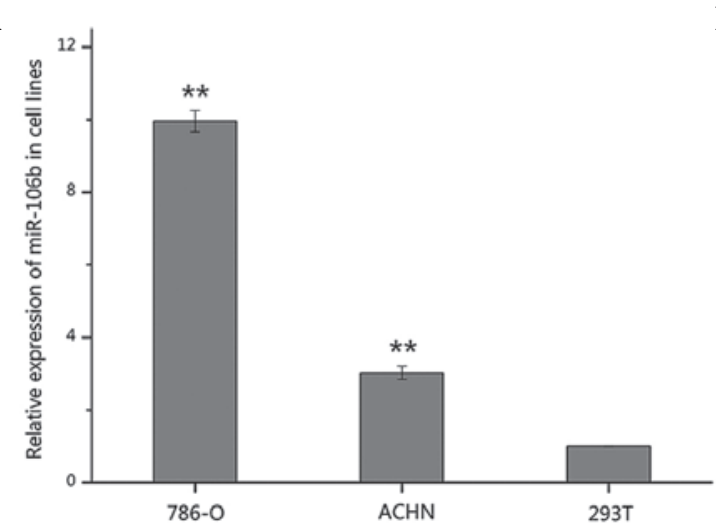

B

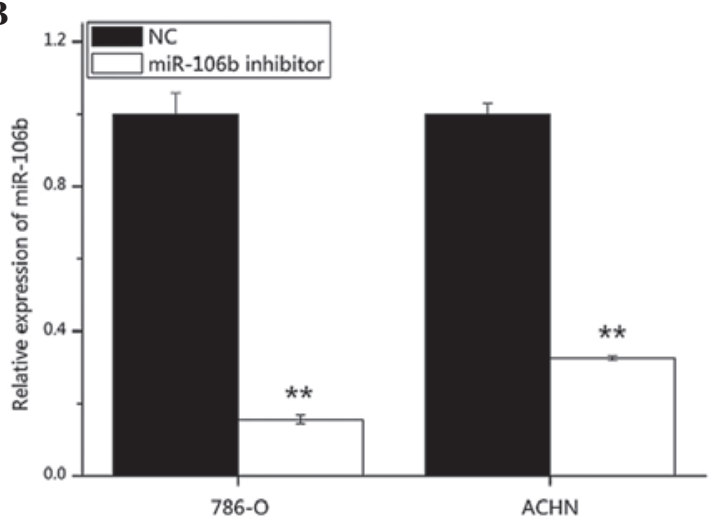

Figure 2. (A) Expression of miR-106b in RCC cell lines (786-O and ACHN) and the normal kidney human embryonic cell line (293T). (B) Relative expression of miR-106b in 786-O and ACHN cells transfected with the miR-106b inhibitor or NC. ${ }^{* *} \mathrm{P}<0.001$. miR-106b, microRNA-106b, RCC, renal cell carcinoma; $\mathrm{NC}$, negative control.

The results revealed that the proliferation of $786-\mathrm{O}$ cells was decreased by $14.37(\mathrm{P}=0.09), 16.70(\mathrm{P}<0.01)$ and $29.61 \%$ $(\mathrm{P}<0.01)$, and the proliferation of ACHN cells was inhibited by $17.74(\mathrm{P}<0.05), 24.86(\mathrm{P}<0.01)$ and $33.96 \%(\mathrm{P}<0.01)$ at 24,48 and $72 \mathrm{~h}$ after transfection of the miR-106b inhibitor, respectively, as compared with the NC group. The results suggested that downregulation of miR-106b significantly suppressed the proliferation of renal cancer cells (Fig. 4).

miR-106b inhibitor induces apoptosis of 786-O and ACHN cells. The effects of the miR-106b inhibitor on apoptosis were determined by flow cytometric analysis. Following transfection of either the miR-106b inhibitor or NC for $48 \mathrm{~h}, 786-\mathrm{O}$ and ACHN cells were harvested, stained and measured. The results revealed that the average apoptotic rate of 786-O cells transfected with the miR-106b inhibitor or NC was 5.03 and
$2.45 \%(\mathrm{P}<0.01)$, while the average apoptotic rate of ACHN cells in the miR-106b inhibitor or NC group was 13.24 vs. $6.59 \%$ $(\mathrm{P}<0.05)$, suggesting that the miR-106b inhibitor induced apoptosis in RCC cells (Fig. 5).

\section{Discussion}

miRNAs are $22 \mathrm{nt}$, single-strand, non-coding RNAs that bind to the 3'-untranslated region of target genes and regulate gene expression by translation inhibition or inducing mRNA degradation (9). There are increasing studies on the crucial role of miRNAs in cancer initiation, progression, metastasis and invasion $(7,23)$. miRNAs are important regulators of all hallmarks of cancer, including cell growth and cell cycle control, evasion of apoptosis, tissue invasion and metastasis, angiogenesis and unlimited replicative potential (7). There are 
A

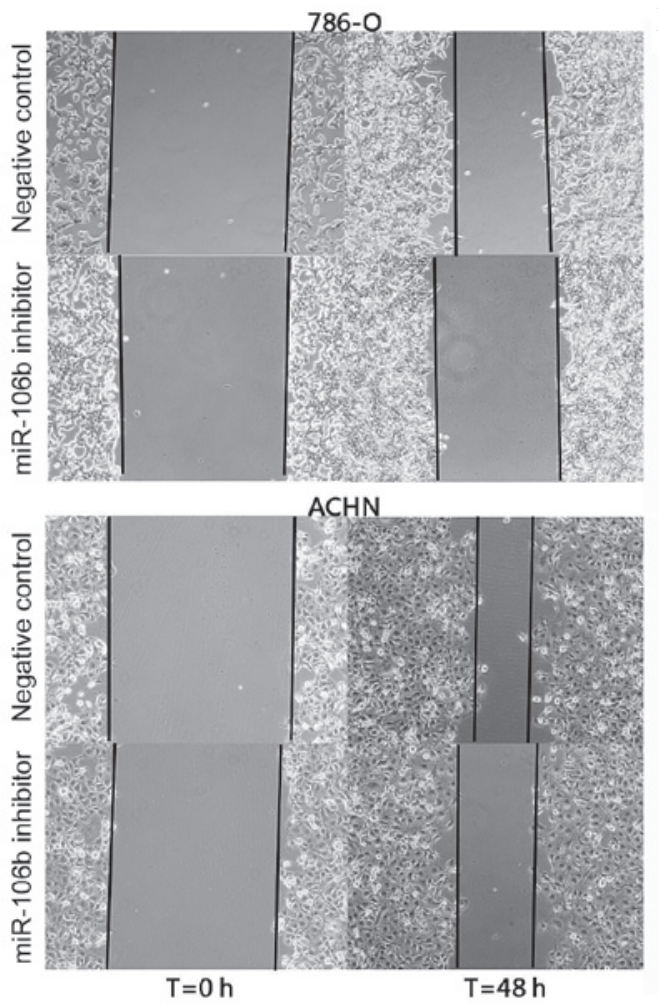

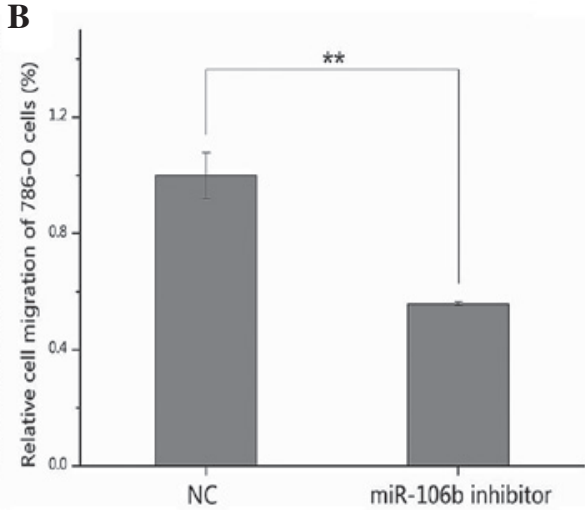

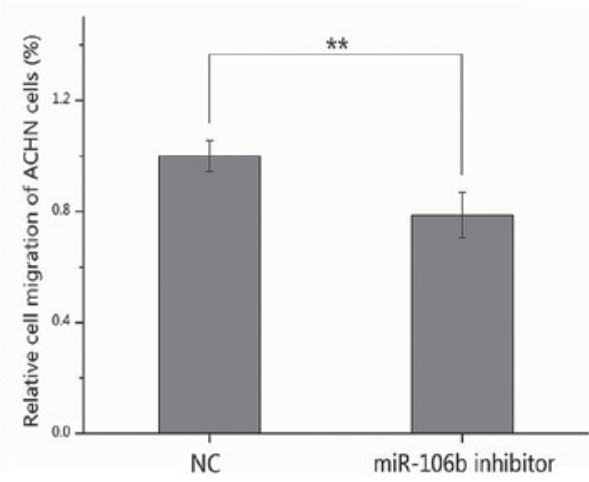

Figure 3. Cell scratch assay. (A) Images of the 786-O and ACHN cells transfected with the miR-106b inhibitor or NC 0 and $48 \mathrm{~h}$ after the scratches were made at the same point. (B) Statistical data of relative cell migration of $786-\mathrm{O}$ and ACHN cells. ${ }^{* *} \mathrm{P}<0.001$. NC, negative control; miR-106b, microRNA-106b.
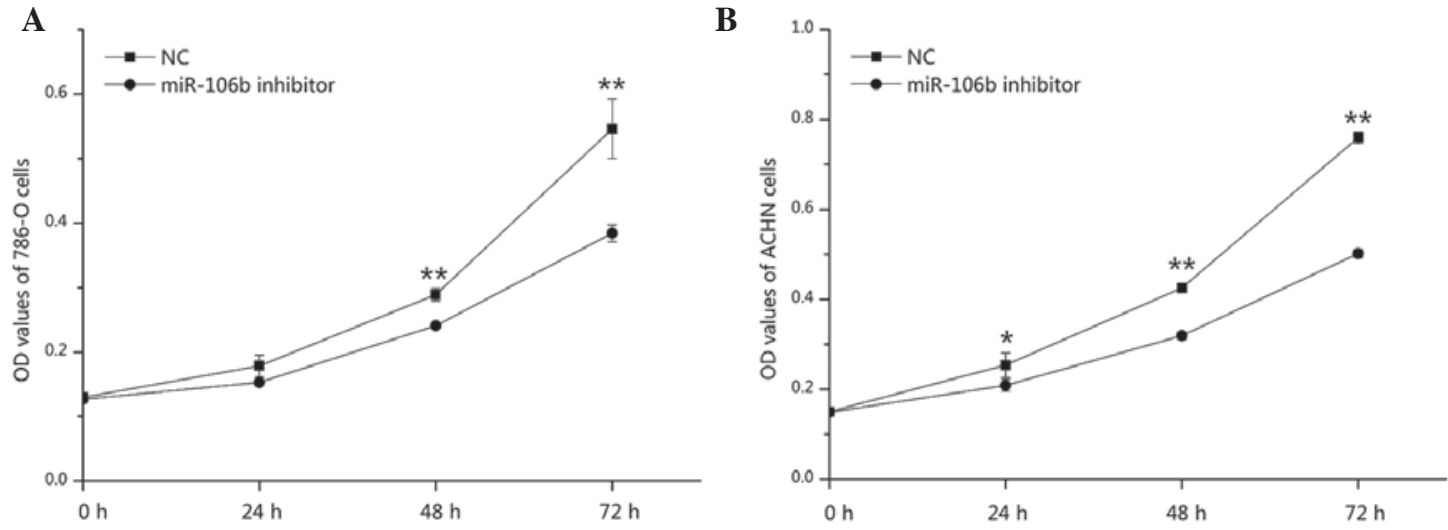

Figure 4. Cell proliferation of (A) 786-O and (B) ACHN transfected with the miR-106b inhibitor or NC was measured by MTT assay at 0, 24, 48 and $72 \mathrm{~h}$ post-transfection. ${ }^{* *} \mathrm{P}<0.001$. miR-106b, microRNA-106b; NC, negative control; MTT, 3-(4,5-dimethylthiazol-2-yl)-2,5-diphenyltetrazolium bromide; OD, optical density.

two essential implications of miRNAs: Firstly, the expression profile studies of miRNAs have demonstrated that upregulated or downregulated miRNAs in RCC, including RCC subtypes may serve as biomarkers for diagnostic, prognostic, predictive and disease monitoring purposes, and secondly, the function and mechanism studies of specific miRNAs could contribute to the development of novel therapies (23).

miR-106b has been reported to be upregulated in tumors of numerous organs (15-21) by comprehensive miRNA profiling. Previous microarray profiles in RCC and adjacent normal tissues have demonstrated a high expression of miR-106b (11-14). However, the expression pattern of miR-106b in RCC has not been verified by RT-PCR and the tumor-associated function of miR-106b remains to be elucidated. In the present study, RT-qPCR was performed to validate the upregulation of miR-106b in RCC tissues and cells, as compared with adjacent normal tissues and HEK-293T cells. In addition, the effects of miR-106b on cell migration, proliferation and apoptosis in RCC cells were examined by wound scratch assay, MTT assay and flow cytometry. The results demonstrated that miR-106b was significantly higher in RCC tissues and cells compared with normal tissues and cells, and the reduction of miR-106b by the synthesized miR-106b inhibitor significantly suppressed cell migration, proliferation and evasion of apoptosis. These results suggested that miR-106b may be a biomarker for RCC 
A

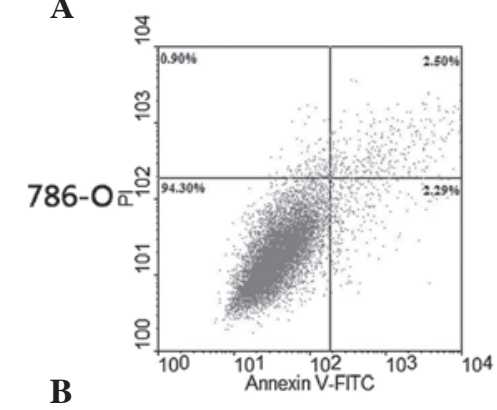

B
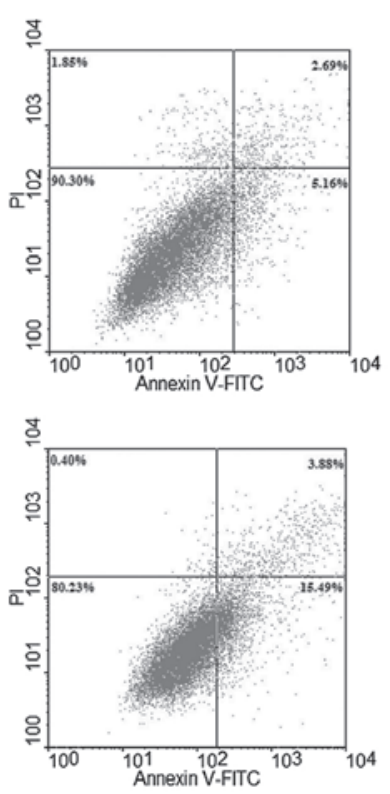
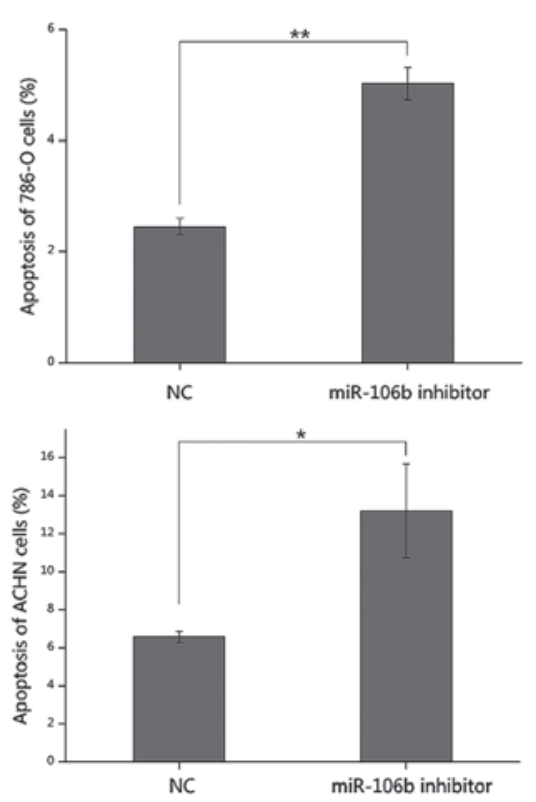

Figure 5. Apoptosis (\%) of (A) 786-O and (B) ACHN cells was measured by flow cytometry. ${ }^{*} \mathrm{P}<0.05 ;{ }^{* * *} \mathrm{P}<0.001$. miR-106b, microRNA-106b; NC, negative control; FITC, fluorescein isothiocyanate.

diagnosis, disease monitoring and prognosis and could be a target for therapeutic purposes.

miRNAs exert their functions on cancer cells mainly depending on their target genes. The various molecular mechanisms of how miR-106b affects tumor initiation, development, metastasis and invasion have been reported in several different types of cancer. In brain cancer, through downregulation of p21/WAF1/Cip1, miRNA-106b was verified to be important in melanoma growth, and grape seed proanthocyanidins acted as an inhibitor of miR-106b thereby inhibiting melanoma growth in vitro and in vivo models (24). Another study identified that overexpression of miR-106b-5p in glioma tumor cells significantly promoted cell proliferation and inhibited cell apoptosis, while knockdown of miR-106b-5p significantly inhibited cell proliferation and enhanced cell apoptosis in vitro and in vivo. Furthermore, the authors found that miR-106b-5p affected cell proliferation by targeting retinoblastoma-like 1 (RBL1) and RBL2 and regulated cell apoptosis by decreasing caspase- 8 (25). The miR-106b-25 miRNA was also found to be associated with prostate cancer progression and disease outcome and may do so by altering apoptosis- (caspase-7, apoptosis-related cysteine peptidase) and focal adhesion-associated pathways $(24,26)$. Epithelial-mesenchymal transition (EMT) describes a transcriptional mechanism that ensures tissue remodeling during embryonic morphogenesis and is considered to be an important step in cancer cell dissemination and metastasis (27). By targeting TWIST1, miR-106b modulates EMT in invasive endometrial cancer cell lines (28). In laryngeal cancer, miR-106b was reported to target RUNX3 and $\mathrm{RB}$ is important in proliferation and invasion of laryngeal carcinoma cells $(29,30)$. Stromal interactions with cancer cells in the microenvironment determine whether cancer cells remain stable or progress into invasive and metastatic tumors (31). miRNA-106b in cancer-associated fibroblasts from gastric cancer function as an oncogene, promoting cell migration and invasion by targeting PTEN (32). One study demonstrated that AAAGUGC seed-containing miRNAs, including miR-106b promote cell expansion, replating capacity and signaling in hematopoietic cells by interference with quantitative proteomics identified sequestosome 1-regulated pathways (33). In hepatocellular carcinoma, miR-106b targeted adenomatous polyposis coli (APC) and downregulation of APC caused accumulation of $\beta$-catenin, which is a major cellular effector of Wnt signaling (34). miR-106b was necessary for hepatocellular carcinoma cell proliferation, anchorage-independent growth, apoptosis (targeting F2F1) and contributed to metastasis and migration by activating EMT $(35,36)$.

In clinical application research, miR-106b in plasma was significantly higher in gastric cancer patients compared with in the control, suggesting that miR-106b may be a new tumor marker for gastric cancer (37-39) and laryngeal cancer (20). Urinary cell-free miRNA-106b has been verified as a novel biomarker for the detection of bladder cancer and the level of urinary miR-106b was associated with advanced tumor stage (40). Increased tumor miR-106b expression was also reported to be associated with disease recurrence in prostate cancer (26), adverse outcomes and a higher risk of systemic spread in osteosarcomas (41).

In conclusion, to the best of our knowledge, the present study is the first to reveal the relative expression and cellular function of miR-106b in RCC. The results in the present study demonstrated that miR-106b was significantly upregulated in RCC tissues and cell lines compared with controls, and inhibition of miR-106b suppressed cell migration and proliferation, although induced cell apoptosis. In addition, the data suggested that miR-106b may not only be a promising biomarker for diagnosis, disease monitoring and prognosis, but may also be a therapeutic target for the treatment of RCC. Further studies are required to examine the roles and target genes of miR-106b in RCC. 


\section{Acknowledgements}

This study was supported by grants from the National Natural Science Foundation of China (grant no. 81101922), Science and Technology Development Fund Project of Shenzhen (grant nos. JCYJ20130402114702124, JCYJ20130402113131201 and JCYJ20150403091443329) and the fund of Guangdong Key Medical Subject.

\section{References}

1. Ridge CA, Pua BB and Madoff DC: Epidemiology and staging of renal cell carcinoma. Semin Intervent Radiol 31: 3-8, 2014.

2. Ferlay J, Shin HR, Bray F, Forman D, Mathers C and Parkin DM: Estimates of worldwide burden of cancer in 2008: GLOBOCAN 2008. Int J Cancer 127: 2893-2917, 2010.

3. Motzer RJ, Bander NH and Nanus DM: Renal-cell carcinoma. N Engl J Med 335: 865-875, 1996.

4. Iwamoto H, Kanda Y, Sejima T, Osaki M, Okada F and Takenaka A: Serum miR-210 as a potential biomarker of early clear cell renal cell carcinoma. Int J Oncol 44: 53-58, 2014.

5. Ljungberg B, Cowan NC, Hanbury DC, Hora M, Kuczyk MA, Merseburger AS, Patard JJ, Mulders PF and Sinescu IC; European Association of Urology Guideline Group: EAU guidelines on renal cell carcinoma: The 2010 update. Eur Urol 58: 398-406, 2010.

6. Linehan WM, Srinivasan R and Schmidt LS: The genetic basis of kidney cancer: A metabolic disease. Nat Rev Urol 7: 277-285, 2010.

7. Fendler A, Stephan C, Yousef GM and Jung K: MicroRNAs as regulators of signal transduction in urological tumors. Clin Chem 57: 954-968, 2011.

8. Oulas A, Karathanasis N, Louloupi A and Poirazi P: Finding cancer-associated miRNAs: Methods and tools. Mol Biotechnol 49: 97-107, 2011.

9. Maher ER: Genomics and epigenomics of renal cell carcinoma. Semin Cancer Biol 23: 10-17, 2013.

10. Rydzanicz M, Wrzesiński T, Bluyssen HA and Wesoly J: Genomics and epigenomics of clear cell renal cell carcinoma: Recent developments and potential applications. Cancer Lett 341: 111-126, 2013.

11. Chow TF, Youssef YM, Lianidou E, Romaschin AD, Honey RJ, Stewart R, Pace KT and Yousef GM: Differential expression profiling of microRNAs and their potential involvement in renal cell carcinoma pathogenesis. Clin Biochem 43: 150-158, 2010.

12. Wulfken LM, Moritz R, Ohlmann C, Holdenrieder S, Jung V, Becker F, Herrmann E, Walgenbach-Brünagel G, von Ruecker A Müller SC and Ellinger J: MicroRNAs in renal cell carcinoma: Diagnostic implications of serum miR-1233 levels. PLoS One 6 : e25787, 2011

13. Muller S and Nowak K: Exploring the miRNA-mRNA regulatory network in clear cell renal cell carcinomas by next-generation sequencing expression profiles. Biomed Res Int 2014: 948408, 2014.

14. Slaby O, Jancovicova J, Lakomy R, Svoboda M, Poprach A, Fabian P, Kren L, Michalek $J$ and Vyzula R: Expression of miRNA-106b in conventional renal cell carcinoma is a potential marker for prediction of early metastasis after nephrectomy. J Exp Clin Cancer Res 29: 1756-9966, 2010.

15. Hui AB, Lenarduzzi M, Krushel T, Waldron L, Pintilie M, Shi W, Perez-Ordonez B, Jurisica I, O'Sullivan B, Waldron J, et al: Comprehensive MicroRNA profiling for head and neck squamous cell carcinomas. Clin Cancer Res 16: 1129-1139, 2010

16. Ji T, Zheng ZG, Wang FM, Xu LJ, Li LF, Cheng QH, Guo JF and Ding XF: Differential microRNA expression by Solexa sequencing in the sera of ovarian cancer patients. Asian Pac J Cancer Prev 15: 1739-1743, 2014

17. Ambs S, Prueitt RL, Yi M, Hudson RS, Howe TM, Petrocca F, Wallace TA, Liu CG, Volinia S, Calin GA, et al: Genomic profiling of microRNA and messenger RNA reveals deregulated microRNA expression in prostate cancer. Cancer Res 68: 6162-6170, 2008.

18. Wang YX, Zhang XY, Zhang BF, Yang CQ, Chen XM and Gao HJ: Initial study of microRNA expression profiles of colonic cancer without lymph node metastasis. J Dig Dis 11: 50-54, 2010

19. Yao Y, Suo AL, Li ZF, Liu LY, Tian T, Ni L, Zhang WG, Nan KJ, Song TS and Huang C: MicroRNA profiling of human gastric cancer. Mol Med Rep 2: 963-970, 2009.
20. Yu X, Wu Y, Liu Y, Deng H, Shen Z, Xiao B and Guo J: miR-21, miR-106b and miR-375 as novel potential biomarkers for laryngeal squamous cell carcinoma. Curr Pharm Biotechnol 15: $503-508,2014$

21. Wang X, Zhang H, Zhang A, Han L, Wang K, Liu R, Yang S, $\mathrm{Pu} \mathrm{P}$, Shen C, Kang C and Yu C: Upregulation of miR-20a and miR-106b is involved in the acquisition of malignancy of pediatric brainstem gliomas. Oncol Rep 28: 1293-1300, 2012.

22. Edge SB, Byrd DR, Compton CC, Fritz AG, Greene FL and Trott A (eds): AJCC Cancer Staging Manual. 7th edition. Springer, New York, NY, pp479-489, 2010.

23. Schaefer A, Stephan C, Busch J, Yousef GM and Jung K: Diagnostic, prognostic and therapeutic implications of microRNAs in urologic tumors. Nat Rev Urol 7: 286-297, 2010.

24. Prasad R and Katiyar SK: Down-regulation of miRNA-106b inhibits growth of melanoma cells by promoting G1-phase cell cycle arrest and reactivation of $\mathrm{p} 21 / \mathrm{WAF} 1 / \mathrm{Cip} 1$ protein. Oncotarget 5: 10636-10649, 2014.

25. Liu F, Gong J, Huang W, Wang Z, Wang M, Yang J, Wu C, Wu Z and Han B: MicroRNA-106b-5p boosts glioma tumorigenesis by targeting multiple tumor suppressor genes. Oncogene 33: 4813-4822, 2014.

26. Hudson RS, Yi M, Esposito D, Glynn SA, Starks AM, Yang Y, Schetter AJ, Watkins SK, Hurwitz AA, Dorsey TH, et al: MicroRNA-106b-25 cluster expression is associated with early disease recurrence and targets caspase-7 and focal adhesion in human prostate cancer. Oncogene 32: 4139-4147, 2013.

27. Kang Y and Massagué J: Epithelial-mesenchymal transitions: Twist in development and metastasis. Cell 118: 277-279, 2004.

28. Dong P, Kaneuchi M, Watari H, Sudo S and Sakuragi N: MicroRNA-106b modulates epithelial-mesenchymal transition by targeting TWIST1 in invasive endometrial cancer cell lines. Mol Carcinog 53: 349-359, 2014.

29. Xu Y, Wang K, Gao W, Zhang C, Huang F, Wen S and Wang B: MicroRNA-106b regulates the tumor suppressor RUNX3 in laryngeal carcinoma cells. FEBS Lett 587: 3166-3174, 2013.

30. Cai K, Wang Y and Bao X: MiR-106b promotes cell proliferation via targeting RB in laryngeal carcinoma. J Exp Clin Cancer Res 30: 1756-9966, 2011.

31. Rubin H: Contact interactions between cells that suppress neoplastic development: Can they also explain metastatic dormancy? Adv Cancer Res 100: 159-202, 2008.

32. Yang TS, Yang XH, Chen X, Wang XD, Hua J, Zhou DL, Zhou B and Song ZS: MicroRNA-106b in cancer-associated fibroblasts from gastric cancer promotes cell migration and invasion by targeting PTEN. FEBS Lett 588: 2162-2169, 2014.

33. Meenhuis A, van Veelen PA, de Looper H, van Boxtel N, van den Berge IJ, Sun SM, Taskesen E, Stern P, de Ru AH, van Adrichem AJ, et al: MiR-17/20/93/106 promote hematopoietic cell expansion by targeting sequestosome 1-regulated pathways in mice. Blood 118: 916-925, 2011.

34. Shen G, Jia H, Tai Q, Li Y and Chen D: miR-106b downregulates adenomatous polyposis coli and promotes cell proliferation in human hepatocellular carcinoma. Carcinogenesis 34: 211-219, 2013.

35. Yau WL, Lam CS, Ng L, Chow AK, Chan ST, Chan JY, Wo JY, $\mathrm{Ng} \mathrm{KT}$, Man K, Poon RT and Pang RW: Over-expression of miR-106b promotes cell migration and metastasis in hepatocellular carcinoma by activating epithelial-mesenchymal transition process. PLoS One 8: e57882, 2013.

36. Li Y, Tan W, Neo TW, Aung MO, Wasser S, Lim SG and Tan TM Role of the miR-106b-25 microRNA cluster in hepatocellular carcinoma. Cancer Sci 100: 1234-1242, 2009.

37. Tsujiura M, Ichikawa D, Komatsu S, Shiozaki A, Takeshita H, Kosuga T, Konishi H, Morimura R, Deguchi K, Fujiwara H, et al: Circulating microRNAs in plasma of patients with gastric cancers. Br J Cancer 102: 1174-1179, 2010.

38. Zhang R, Wang W, Li F, Zhang H and Liu J: MicroRNA-106b 25 expressions in tumor tissues and plasma of patients with gastric cancers. Med Oncol 31: 243, 2014

39. Cai H, Yuan Y, Hao YF, Guo TK, Wei X and Zhang YM: Plasma microRNAs serve as novel potential biomarkers for early detection of gastric cancer. Med Oncol 30: 452, 2013.

40. Zhou X, Zhang X, Yang Y, Li Z, Du L, Dong Z, Qu A, Jiang X, Li P and Wang C: Urinary cell-free microRNA-106b as a novel biomarker for detection of bladder cancer. Med Oncol 31: 197, 2014.

41. Arabi L, Gsponer JR, Smida J, Nathrath M, Perrina V, Jundt G, Ruiz C, Quagliata L and Baumhoer D: Upregulation of the miR-17-92 cluster and its two paraloga in osteosarcoma - reasons and consequences. Genes Cancer 5: 56-63, 2014 